\title{
Table des Groupes
}

\begin{tabular}{|c|c|c|c|}
\hline & No & & ame et Fou contre Dame. \\
\hline II. & & & Dame et Fou contre Dame et aut \\
\hline III $^{1}$ & $"$ & & valier contre Dame. \\
\hline IV & $"$ & $14-25$ & Dame et Cavalier contre Dame et autres for \\
\hline $\mathrm{V}$ & " & & $\begin{array}{l}\text { Dame, Cavalier et Pion contre Dame et autr } \\
\text { forces. }\end{array}$ \\
\hline $\mathrm{VI}^{2}$ & $"$ & $35-49$ & $\begin{array}{l}\text { Dame et autres forces contre Dame et autres } \\
\text { forces. }\end{array}$ \\
\hline VII & & $50-53$ & Dame et Pions contre Dame et Pions. \\
\hline VIII & $"$ & & $\begin{array}{l}\text { Fou, Cavalier et Pions contre des Pions do } \\
\text { un atteint la case de transformation. }\end{array}$ \\
\hline IX & $"$ & $60-63$ & $\begin{array}{l}\text { Fou, Cavalier et Pions contre Dame et autr } \\
\text { forces. }\end{array}$ \\
\hline $\mathbf{X}$ & $"$ & $64-65$ & $\begin{array}{l}\text { Deux Cavaliers et Pions contre Dame et autr } \\
\text { forces. }\end{array}$ \\
\hline $\mathbf{X I}$ & " & & Tour, Fou et $\mathrm{Pi}$ \\
\hline XII & $"$ & & $\begin{array}{l}\text { Tour, Cavalier et Pions contre Dame et autr } \\
\text { forces. }\end{array}$ \\
\hline XIII & " & $80-82$ & $\begin{array}{l}\text { Trois pièces mineures et Pions contre Dame } \\
\text { et autres forces. }\end{array}$ \\
\hline XIV & $"$ & $83-85$ & $\begin{array}{l}\text { Une piece mineure et Pions contre Tour, avec } \\
\text { ou sans Pions. }\end{array}$ \\
\hline XV & $"$ & $86-89$ & $\begin{array}{l}\text { Deux pièces mineures et Pions contre Tour et } \\
\text { Pions. }\end{array}$ \\
\hline XVI & " & $90-108$ & $\begin{array}{l}\text { Manoeuvres tactiques pour faire arriver un } \\
\text { Pion a Dame. }\end{array}$ \\
\hline XVll & " & $109-115$ & Etudes diverses de Gain. \\
\hline XVIII & " & $116-121$ & Etudes diverses de Nullité. \\
\hline$\underset{X^{\prime} X^{8}}{\mathbf{X}}$ & & $\left.\begin{array}{r}122-135 \\
136-150\end{array}\right\}$ & ides $c$ \\
\hline
\end{tabular}

1 Dans les groupes III, IV, VII, XI, figurent en première ligne les études comprenant des Pions qui se transforment en Dames.

- Les compositions de ce groupe procèdent de sacrifices amenant le gain de la Dame, soit en obligeant celle-ci à se déplacer ( $\mathrm{N}^{\circ} 35-40$ ), soit en la privant d'une pièce défensive ( $\left.\mathrm{N}^{\circ} 44,46,48\right)$, soit aussi en découvrant une ligne qui la laisserait sans protection (No 41, 44, 47,49 ), ou bien en obstruant une case, ce qui, entravant les mouvements du Roi noir, a également pour conséquence la perte de la Dame (No 41, 42, 43, 44, 45).

${ }^{3}$ Les études de ce groupe présentent des positions finales pures et économiques sans Pions inactifs. 


\section{Verzeichnis der Gruppen}

\begin{tabular}{|c|c|c|c|}
\hline I & & & Dame und Läufer gegen Dame \\
\hline II & $"$ & & $\begin{array}{l}\text { Dame und Lăufer gegen Dame und andere } \\
\text { Streitkräfte. }\end{array}$ \\
\hline III $^{1}$ & & $9-13$ & Dame und Springer gegen Dame. \\
\hline IV & $"$ & $14-25$ & $\begin{array}{l}\text { Dame und Springer gegen Dame und andere } \\
\text { Streitkräfte. }\end{array}$ \\
\hline V & $"$ & $26-34$ & $\begin{array}{l}\text { Dame, Springer und Bauer gegen Dame und } \\
\text { andere Streitkrafte. }\end{array}$ \\
\hline $\mathrm{VI}^{2}$ & $"$ & $35-49$ & $\begin{array}{l}\text { Dame und andere Streitkräfte gegen Dame und } \\
\text { andere Streitkrafte. }\end{array}$ \\
\hline VII & & $50-53$ & Dame und Bauern gegen Dame und Bauern. \\
\hline VIII & $n$ & & $\begin{array}{l}\text { Läufer, Springer und Bauern gegen Bauern, von } \\
\text { welchen einer das Umwandlungsfeld erreicht. }\end{array}$ \\
\hline IX & $"$ & $60-63$ & $\begin{array}{l}\text { Lăufer, Springer und Bauern gegen Dame und } \\
\text { andere Streitkräfte. }\end{array}$ \\
\hline $\mathbf{X}$ & " & $64-65$ & $\begin{array}{l}\text { Zwei Springer und Bauern gegen Dame und } \\
\text { andere Streitkräfte. }\end{array}$ \\
\hline $\mathbf{X I}$ & ", & $66-$ & Turm, Lăufer und Bauern gegen Dame und Bauern. \\
\hline XII & " & & $\begin{array}{l}\text { Turm, Springer und Bauern gegen Dame und } \\
\text { andere Streitkräfte. }\end{array}$ \\
\hline XIII & " & $80-82$ & $\begin{array}{l}\text { Drei kleine Figuren und Bauern gegen Dame } \\
\text { und andere Streitkräfte. }\end{array}$ \\
\hline XIV & $"$ & $83-85$ & $\begin{array}{l}\text { Eine kleine Figur und Bauern gegen Turm, mit } \\
\text { oder ohne Bauern. }\end{array}$ \\
\hline XV & $"$ & & $\begin{array}{l}\text { Zwei kleine Figuren und Bauern gegen Turm } \\
\text { und Bauern. }\end{array}$ \\
\hline XVI & $"$ & $90-108$ & $\begin{array}{l}\text { Taktische Manöver, um einen Bauer zur Dame } \\
\text { zu fuhren. }\end{array}$ \\
\hline XVII & " & $109-115$ & Verschiedenartige Gewinnstudien. \\
\hline XVIII & & $116-121$ & Verschiedenartige Remisstudien. \\
\hline$\underset{X^{3}}{\mathrm{XIX}}$ & $"$ & $\begin{array}{l}122-135 \\
136-150\end{array}$ & \\
\hline
\end{tabular}

'In den Gruppen III, IV, VII, XI figurieren in erster Linie diejenigen Studien, bei welchen sich Bauern in Damen umwandeln.

${ }^{2}$ Die Kompositionen dieser Gruppe sind charakterisiert durch Opfer, welche den Gewinn der Dame vorbereiten, und zwar entweder dadurch, $\mathrm{daB}$ die Dame gezwungen wird, ihren Platz zu wechseln (Mr. 35- 40), oder daB ein sie schtitzender Stein abgelenkt wird (Nr. 44, 46, 48), oder daß eine sie preisgebende Linie geöffnet wird (Nr. 41, 44, 47, 49), oder endlich, daß dem schwarzen König ein Fluchtfeld genommen wird, was ebenfalls den Damenverlust verursacht (Nr. 41, 42, 43, 44, 45).

${ }^{3}$ Die Studien dieser Gruppe weisen reine und ökonomische Schlubstellungen ohne untătige Bauern auf. 
Quatre êtudes présentées comme "Première publication", ont été publiées alors que le présent ouvrage était déjả en cours d'impression:

$$
\begin{aligned}
& \text { No } 5 \text { dans la „Bohemia" - Juin } 1908 \\
& \text { No } 35 \text { dans la "Deutsche Schachzeitung" - Juillet } 1908
\end{aligned}
$$

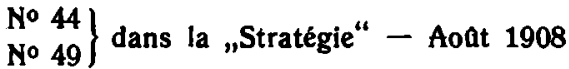

Wahrend der Drucklegung des Buches sind vier Studien anderweit veroffentlicht worden, welche als "Erste Veroffentlichung" bezeichnet sind:

Nr. 5 in der "Bohemia“ - Juni 1908

Mr. 35 in der "Deutschen Schachzeitung" - Jull 1908

$\left.\begin{array}{l}\text { Mr. } 44 \\ \text { Nr. } 49\end{array}\right\}$ in der "Stratégie“ - August 1908 